\title{
Inoculation of Soil Cyanobacteria Improves Fertility of a Soil Mixed with Copper Tailing Sands
}

\author{
Claudia Ortiz $^{1}$, Uro Ledesma ${ }^{1}$, Darlyng Pontigo ${ }^{1}$ \\ ${ }^{1}$ Biology Department/University of Santiago de Chile \\ Alameda 3363, Santiago, Chile \\ Claudia.ortiz@usach.cl; uro.ledesma@usach.cl \\ Darling.pontigo@usach.cl
}

\begin{abstract}
Industrial activities such as mining provoke soil degradation which can be restored by applying cyanobacteria as inoculants to promote biocrust development. However, previous to the field applications, there is a need to determine the cyanobacterial suitable species under laboratory conditions. In this investigation, a culture of Trichormus sp. isolated from environmental samples was inoculated on a soil mixed with copper tailing sands. The establishment of the cyanobacteria on the substrate was determined by confocal microscopy, and germination and growth of Polypogon australis, a tailing storage facility (TSF) natural colonizer were determined. In addition, the total nitrogen content $(\mathrm{N})$, phosphorus available $(\mathrm{P})$ and organic matter (OM) content of the inoculated substrates was measured after 30 days. The results showed that the cyanobacterial culture increases the speed but not the cumulative germination of $P$. australis, and generates an increase of available $\mathrm{P}$, total $\mathrm{N}$ and $\mathrm{OM}$ of the mixed soil. The improvement in soil fertility and stability of tailing sands supports the use of cyanobacteria to restore degraded or mining polluted soils.
\end{abstract}

Keywords: cyanobacteria, biocrusts, soil degradation, mining activities, land rehabilitation

\section{Introduction}

Tailing storage facilities (TSF) are large impoundments used to deposit residues generated by mineral extraction (Sheoran et al., 2010). The solid material left after the sludge has dried contains hazardous elements which affect the sites nearby when dispersed by wind or waster erosion (Hesketch et al., 2010, Mani and Kumar, 2014). The establishment of plants and microorganisms in this type of substrates is impeded by physical and chemical factors such as high salinity, the content of heavy metals, together with the occurrence of extreme temperatures and low rainfall (Mendez et al., 2008). However, the colonization and establishment of plant species has been observed in these types of substrates and in soils affected by tailing sands (Wang et al., 2017). One example of a TSF successful colonizer is Polypogon australis, a Chilean native non-endemic facultative metalophyte (Ortiz-Calderón et al., 2008; Pollard et al., 2014; Jara-Hermosilla et al., 2017). soil

The successful colonisation of vascular plants in degraded soils has been attributed to the formation of biological

crusts (BSC) that are a complex and intimate association between soil particles and microorganisms such as algae, lichens, mosses and fungi whose formation can be promoted by cyanobacteria (Belnap and Lange, 2003). BSC constitute a dominant biotic component that can improve the physical structure of soil reducing soil erosion (Zhang et al., 2017). BSCs play an important role in the bio-geochemistry of elements modulating the carbon and the nitrogen cycle (Maestre and Cortina, 2002; Castillo-Monroy et al. 2010) and are considered responsible for the autotrophic carbon and nitrogen fixation in drylands (Bowker et al., 2005). Taking in account this background, the use of BSC forming microorganisms as soil inoculants is a promising tool to improve soil quality and counteract soil degradation (Maestre et al., 2017; Rossi et al., 2017).

Cyanobacteria (CB) are a diverse group of oxygenic photosynthetic prokaryotes capable of colonizing a large number of soils including nutrient-poor substrates (Singh, 2014; Rossi, et al., 2017). These organisms are a rich source of carotenoids, fatty acids, proteins, polysaccharides and other biomolecules (Hashtroudi et al., 2013). It has also been observed that cyanobacteria produce phytohormones such as 3-indole acetic acid (IAA) (Hashtroudi et al., 2013) and extracellular polymers (EPS) (Pereira et al., 2009; Gauri et al., 2012). The EPS are released during the growth of the CB fulfilling a function of cellular adhesion to the soil inducing the formation of biological crusts (Chen et al., 2014, Singh, 
2014). The anionic nature of the EPS is responsible of metals immobilization (Gauri et al., 2012) as well as the water retention in the substrates, maintaining or improving the quality of the soils and facilitating the growth of the plants (Singh, 2014). Although the beneficial effect of cyanobacteria on plants establishment has been widely reported (Prasanna et al., 2015), there are also findings of a negative interaction (allellopathy) between some cyanobacteria species and plants (Smith and Doan, 1999).

In this work, we examined the germination and growth of $P$. australis plants on a soil mixed with copper tailing sands and inoculated with a culture of the cyanobacterium Trichormus sp. We discuss about the effect of the inoculum on the content of nutrients in the substrate and the use of cyanobacterisation for the remediation of soils degraded by the mining industry.

\section{Methodology}

\subsection{Cyanobacteria cultures and soil preparation}

A BG-11 medium culture of the cyanobacteria Trichormus sp. was prepared from bacteria isolated from a soil sample from the Coquimbo Region in the North of Chile. The culture was incubated for 2 weeks at $20^{\circ}$ to $30^{\circ} \mathrm{C}$ and $120 \mathrm{rpm}$ with a photoperiod of $12 \mathrm{~h}$ light:12h darkness. For the soil preparation, three groups of 70 wells were prepared with a mix of 50:50 autoclaved standard soil and tailing sands. The standard soil consisted on a mixture of sand:commercial soil in an 80:20 proportion. The composition of the tailings sand used is shown in Table 1.

Table 1: Chemical parameters of the tailing sand used in the experiments.

\begin{tabular}{|c|c|c|c|c|c|c|c|c|c|c|}
\hline pH & EC & OM & $\mathrm{N}-\mathrm{NO}^{3}$ & Olsen-P & Cd & $\mathbf{C u}$ & Mn & $\mathbf{N i}$ & $\mathbf{P b}$ & $\mathbf{Z n}$ \\
\hline & $\mathrm{mScm}^{-1}$ & $\%$ & $\mathrm{mgKg}^{-1}$ & $\mathrm{mgKg}^{-1}$ & $\mathrm{mgKg}^{-1}$ & $\mathrm{mgKg}^{-1}$ & $\mathrm{mgKg}^{-1}$ & $\mathrm{mgKg}^{-1}$ & $\mathrm{mgKg}^{-1}$ & $\mathrm{mgKg}^{-1}$ \\
\hline 8.3 & 45.6 & 1.0 & 216.5 & 21.7 & 2.4 & 1359.2 & 277.1 & 33.5 & 11.7 & 52.9 \\
\hline
\end{tabular}

\subsection{Soil cyanobacteria inoculation and visualization}

The soil prepared on wells was inoculated with $4 \mathrm{~mL}$ of the cyanobacteria culture (equivalent to $2.14 \mathrm{mgL}^{-1}$ of Chl-a) and surface irrigated by spraying $2 \mathrm{~mL}$ of water daily during 20 days. To determine the presence of cyanobacteria in the soil, three samples were randomly taken with a spatula (approximately $5 \mathrm{mg}$ of the $5 \mathrm{~mm}$ surface layer) from different wells and placed on a slide to seal the sample with a coverslip and tape, and was covered with Immersol ${ }^{\circledR} 518 \mathrm{~F}$ (Zeiss) immersion oil. The observation was made with an Axio Observer.Z1 / 7 microscope (Zeiss) through the objective PlanApochromat 40x / 1.4 Oil DIC (UV) VIS-IR M27. The images were obtained using the LSM800 MA-Pmt2 (Zeiss) device with an argon-krypton laser of $561 \mathrm{~nm}$ maximum excitation. The excitation wavelength employed was $554 \mathrm{~nm}$ and the emission wavelength was $587 \mathrm{~nm}$; which correspond to the fluorescence properties of the accessory pigment phycoerythrin (Bordowitz and Montgomery, 2010). The acquisition of optical sections (focal planes), optical series (all optical cuts obtained from the same focal plane), stereoscopic 3D images and the sum of the total fluorescence of all the optical series was made by the software incorporated in the ZEN 2.3 (Blue edition, Zeiss). Different focal planes for each sample were randomly quantified. The fluorescence obtained was divided by the total volume of the sample $\left(\mu \mathrm{m}^{3}\right)$ to obtain the total fluorescence per sample. The measurements were performed in triplicate.

\subsection{Seed germination and plant growth}

Twenty days after the cyanobacterial inoculation, each well was seeded with 15 seeds of P. australis. Three experimental groups were prepared: wells with soil mixed with tailings sands; wells with soil mixed with tailings sands plus BG-11; and wells with soil mixed with tailing sands and inoculated. Also, a third group of seed were sown in standard soil (80:20 sand:commercial soil mixture). The monitoring of germination and plant growth was performed up to 4 weeks. Once the seeds were sown, the cumulative germination was determined up to $90 \%$ of the seeds reached $1 \mathrm{~cm}$ long in its coleoptile, and then the plant height was recorded once every 5 days up to 25 days, measuring the length between the point of contact with the ground and the upper apical end. 


\subsection{Soil characterization}

To measure the organic matter of the substrates, $500 \mathrm{mg}$ of the sample was dried at $60^{\circ} \mathrm{C}$ for 72 hours, and $5 \mathrm{~mL}$ of $0.5 \mathrm{M} \mathrm{K}_{2} \mathrm{Cr}_{2} \mathrm{O}_{7}$ were added to each sample (Walkley and Black, 1947). In an Erlenmeyer flask, $10 \mathrm{~mL}$ of $96 \% \mathrm{H}_{2} \mathrm{SO}_{4}$ were added under stirring and allowed to stand for 30 minutes, then $35 \mathrm{~mL}$ of Mili-Q water were added and left to rest for 24 hours, finally the absorbance at $600 \mathrm{~nm}$ of the supernatant of each sample was measured (Eyherabide et al., 2014). Each determination was made in triplicate. The available nitrogen and phosphorus content was determined in dried and sieved samples using the Kjeldhal method for nitrogen and P Olsen for phosphorus (Honda, 1962; Olsen et al., 1954).

\subsection{Statistical analysis}

A non-parametric Kruskal-Wallis test with a Dunn multiple comparison, or a two-way ANOVA using Tukey's multiple comparison test were applied. For all results, $\mathrm{p}<0.05$ was considered. All data were processed using the GraphPad Prism 6.01 software (GraphPad Software, Inc., San Diego, USA).

\section{Results}

\subsection{Cyanobacterial soil colonization}

Figure 1 shows representative images of each treatment were fluorescence can only be seen when the substrate was inoculated with the cyanobacteria (Fig $1 \mathrm{E}$ and $1 \mathrm{~F})$.
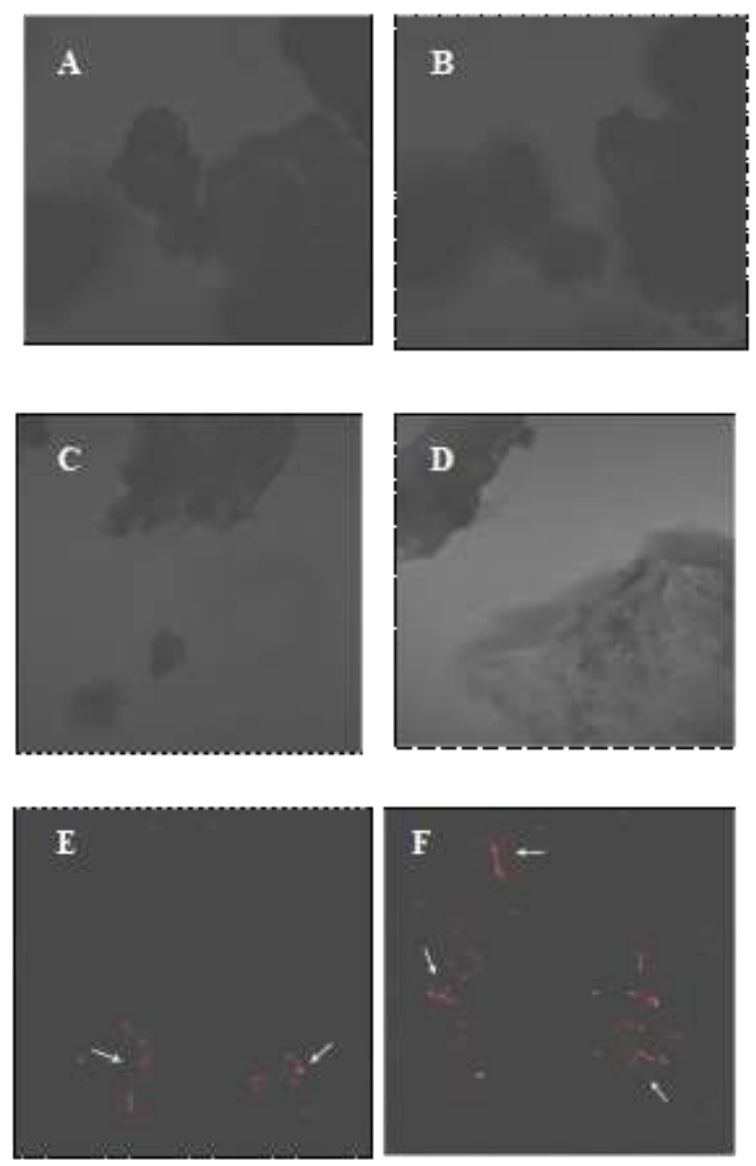

Fig. 1: Visualization by confocal microscopy of soil colonization by Trichormus sp.(A) Control water day 1; (B) Control water day 20; (C) Control BG11day 1; (D) Control BG11 day 20; (E) soil inoculated day 1; (F) soil inoculated day 20. White arrows indicate point 
to filaments of Trichormus sp. Exposed visualized phycoerythrin pigment: $554 \mathrm{~nm}$ Em: $587 \mathrm{~nm}$. The images of each panel are representative of the total of images taken for each treatment.

\subsection{Seed germination and plant growth}

Figure 2 shows the percentage of germination of the seeds in the different treatments. From day 6, germination of seeds on standard soil was significantly higher with respect to treatments. The cumulative germination on standard soil was $90.7 \%$, while in the treatments, the highest germination percentage was observed in soil mixed with tailings sands plus BG11 (71\%). The inoculation of the soil mixed with sands of tailings did not significantly affect the germination of $P$ australis (63\%). However, the mean time of germination in soil mixed with sands of tailings and inoculated was significantly lower with respect to soil without inoculation (10.2 days and 9.6 days, respectively).

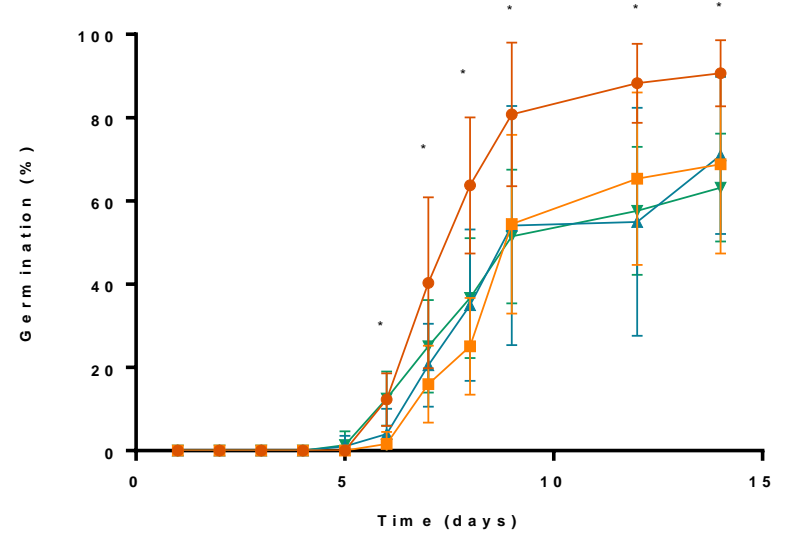

Fig. 2: Cumulative germination of $P$. australis in 14 days. Standard soil (red circles), soil mixed with tailings sands (orange squares), soil mixed with tailings sands plus BG-11 (light blue triangles) and soil mixed with tailing sands and inoculated (inverted green triangle). The statistically significant differences are represented with $(*)(\mathrm{p}<0.05)$.

Figure 3 shows the growth of post-germination plants in the different substrates. It was observed that the plants grew more in the inoculated soil mixed with tailing sands, with significantly higher values between days 11 and 16 . The plants grown in soil mixed with tailing sands and inoculated presented up to three times more protein content per mg of dry weight than the plants grown in the controls, standard soil and mixed soil without inoculation (data not shown).

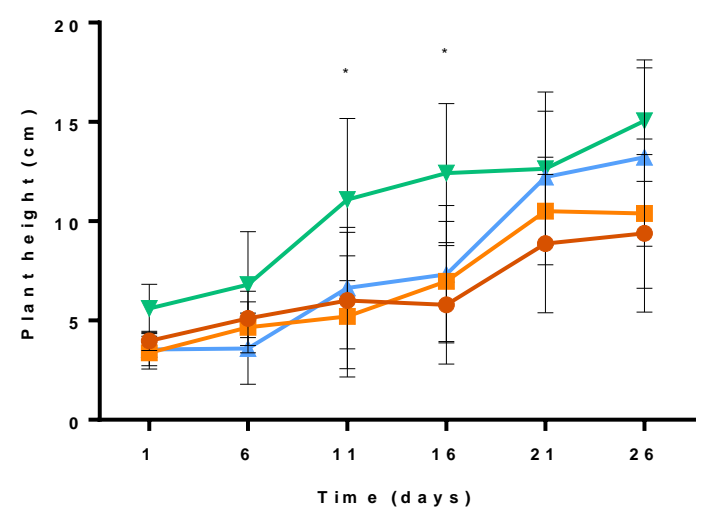

Fig. 3: Height of $P$. australis up to 26 days. Standard soil (red circles), soil mixed with tailings sands (orange squares), soil mixed with tailing sands plus BG-11 (light blue triangles) and soil mixed with tailing sands and inoculated (inverted green triangle). $\mathrm{n}=25$ The statistically significant differences are represented with $(*)(\mathrm{p}<0.05)$.

\subsection{Soil characterization}

Table 2 shows the concentrations of available nitrogen $(\mathrm{N}-\mathrm{KCl})$, total nitrogen $(\mathrm{NT})$, total phosphorous (P-Olsen) and organic matter $(\mathrm{OM})$ of the substrates used in the experiments at initial and final time. At initial time only 
significant differences were observed between standard soil and the experimental soils. At the end of the experiment (day 26), the available nitrogen $(\mathrm{N}-\mathrm{KCl})$, available phosphorus and organic matter were significantly higher in soil mixed with tailings and inoculated sands.

Table 2: Content available nitrogen $(\mathrm{N}-\mathrm{KCl})$, total nitrogen $(\mathrm{NT})$, available phosphorous (P-Olsen) and organic matter $(\mathrm{OM})$ of standard and experimental soils. Each letter represents significant differences.

\begin{tabular}{|c|c|c|c|c|c|c|c|c|}
\hline & \multicolumn{2}{|c|}{$\begin{array}{c}\text { N-KCl } \\
(\mathrm{mg} / \mathrm{Kg}) \\
\end{array}$} & \multicolumn{2}{|c|}{$\begin{array}{c}\text { Total N } \\
(\%)\end{array}$} & \multicolumn{2}{|r|}{$\begin{array}{l}\text { P-Olsen } \\
\text { (mg/Kg) }\end{array}$} & \multicolumn{2}{|r|}{$\begin{array}{l}\text { OM } \\
(\%)\end{array}$} \\
\hline & Initial & Final & Initial & Final & Initial & Final & Initial & Final \\
\hline Standard soil & $166,3 \pm 2,5^{\mathrm{a}}$ & $154 \pm 5^{\mathrm{a}}$ & $0,29 \pm 0,04^{\mathrm{a}}$ & $0,22 \pm 0,01^{\mathrm{a}}$ & $14,95 \pm 1,06^{\mathrm{a}}$ & $18,3 \pm 0,28^{\mathrm{a}}$ & $8,71 \pm 0,25^{\mathrm{a}}$ & $8,94 \pm 0,72^{\mathrm{a}}$ \\
\hline $\begin{array}{l}\text { Soil mixed } \\
\text { with TS }\end{array}$ & $140 \pm 5^{\mathrm{b}}$ & $105 \pm 5^{\mathrm{b}}$ & $0,16 \pm 0,02^{\mathrm{b}}$ & $0,16 \pm 0,01^{\mathrm{b}}$ & $8,05 \pm 0,07^{b}$ & $8,85 \pm+0,07^{b}$ & $7,08 \pm 0,16^{\mathrm{b}}$ & $5,7 \pm 0,33^{\mathrm{c}}$ \\
\hline $\begin{array}{l}\text { Soil mixed } \\
\text { with TS- } \\
\text { BG11 }\end{array}$ & $140 \pm 5^{\mathrm{b}}$ & $175 \pm 5^{\mathrm{c}}$ & $0,16 \pm 0,02^{b}$ & $0,11 \pm 0,01^{\mathrm{b}}$ & $8,05 \pm 0,07^{\mathrm{b}}$ & $8,2 \pm 0,14^{b}$ & $7,08 \pm 0,16^{b}$ & $7,77 \pm 0,23^{b}$ \\
\hline $\begin{array}{l}\text { Soil mixed } \\
\text { with TS } \\
\text { inoculated }\end{array}$ & $140 \pm 5^{b}$ & $224 \pm 5^{\mathrm{d}}$ & $0,16 \pm 0,02^{b}$ & $0,14 \pm 0,01^{\mathrm{b}}$ & $8,05 \pm 0,07^{\mathrm{b}}$ & $10,35 \pm 0,21^{\mathrm{c}}$ & $7,08 \pm 0,16^{\mathrm{b}}$ & $9,14 \pm 0,04^{\mathrm{a}}$ \\
\hline
\end{tabular}

TS: tailing sands; BG11: nutrient media

\section{Conclusion}

The growth of the cyanobacterium Trichormus sp in a soil mixed with copper tailing sands increases the speed of germination of $P$. australis and stimulates the growth of the plants. On the other hand, the presence of cyanobacteria in the soil mixed with tailing sands mediates an increase of the available phosphorus, the total and available $\mathrm{N}$ and of the organic matter of the soil mixed with tailing sands.

\section{Acknowledgements}

We thank Project Fondef IT17M10006 for the financial support.

\section{References}

[1] Belnap, J \& Lange, OL (2003), Biological Soil Crust: structure function and management, Springer, Berlin, Heidelberg. First Edition, pp. 506.

[2] Bordowitz J. R., Montgomery B. L. (2010). Exploiting the autofluorescent properties of photosynthetic pigments for analysis of pigmentation and morphology in live Fremyella diplosiphon cells. Sensors 10, pp. 6969-6979

[3] Bowker,M., Belnap J, Davidson, D W. \& Phillips S.l. (2005) Evidence for micronutrient limitation of biological soil crusts: importance to arid-lands restoration. Ecological Applications, vol. 15, pp. 1941-1951

[4] Castillo-Monroy, A. P., Maestre, F. T., Delgado-Baquerizo, M., \& Gallardo, A. (2010). Biological soil crusts modulate nitrogen availability in semi-arid ecosystems: insights from a Mediterranean grassland. Plant and Soil, vol. 333, no. 12, pp. 21-34

[5] Chen, L., Rossi, F., Deng, S., Liu, Y., Wang, G., Adessi, A., \& De Philippis, R. (2014). Macromolecular and chemical features of the excreted extracellular polysaccharides in induced biological soil crusts of different ages. Soil Biology and Biochemistry, vol. 78, pp. 1-9

[6] Eyherabide, M.; Saínz, H.; Barbieri, P.; Echevarría, H. E. 2014. Comparación de métodos para determinar carbono orgánico en suelo. Ciencia del suelo 3, no. 1, pp. 13-19

[7] Gauri, S. S., Mandal, S. M., \& Pati, B. R. (2012). Impact of Azotobacter exopolysaccharides on sustainable agriculture. Applied Microbiology and Biotechnology, vol. 95, no.2, 331-338

[8] Hashtroudi, M. S., Ghassempour, A., Riahi, H., Shariatmadari, Z., \& Khanjir, M. (2013). Endogenous auxins in plant growth-promoting Cyanobacteria-Anabaena vaginicola and Nostoc calcicola. Journal of Applied Phycology, vol. 25, no. 2, pp. 379-386 
[9] Hesketh A.H., Broadhurst J.L., Harrison S.T.L. (2010). Mitigating the generation of acid mine drainage from copper sulfide tailings impoundments in perpetuity: A case study for an integrated management strategy. Miner Eng. 23:225.

[10] Honda, C. (1962). Rapid determination of nitrogen in soil by Kjeldahl method. J. Sci. Soil Manure, vol. 33, no. 1, pp. 195-200

[11] Jara-Hermosilla, D., Barros-Vásquez, D., Muñoz-Rojas, A., Castro-Morales, S., \& Ortiz-Calderón, C. (2017). Enzymatic reduction of hydrogen peroxide on Polypogon australis plants grown in a copper mining liquid waste. South African Journal of Botany, vol. 109, pp.42-49

[12] Maestre, F. T., \& Cortina, J. (2003). Small-scale spatial variation in soil $\mathrm{CO}_{2}$ efflux in a Mediterranean semiarid steppe. Applied Soil Ecology, vol. 23, no.3, pp. 199-209.

[13] Maestre, F. T., Sole, R., \& Singh, B. K. (2017). Microbial biotechnology as a tool to restore degraded drylands. Microbial biotechnology, vol. 10, no. 5, pp. 1250-1253

[14] Mani, D., and Kumar, C. (2014). Biotechnological advances in bioremediation of heavy metals contaminated ecosystems: an overview with special reference to phytoremediation. Int J Environ Sci Technol. 11:843.

[15] Mendez, M.O., Neilson J.W. and Maier R.M. (2008). Characterization of a Bacterial Community in an Abandoned Semiarid Lead-Zinc Mine Tailing Site. App. Env. Microbiol. 74:3899.

[16] Olsen, S. R., Cole, C. V, Watandbe, F., \& Dean, L. (1954). Estimation of Available Phosphorus in Soil by Extraction with sodium Bicarbonate. Journal of Chemical Information and Modeling, vol. 53, no. 9, pp. 1689-1699

[17] Ortiz-Calderón, C., Alcaide, O., Li Kao, J. (2008). Copper distribution in leaves and roots of plants growing on a copper mine-tailing storage facility in northern Chile. Rev Chil Hist Nat. 81:489.

[18] Pereira, S., Zille, A., Micheletti, E., Moradas-Ferreira, P., De Philippis, R., \& Tamagnini, P. (2009). Complexity of cyanobacterial exopolysaccharides: Composition, structures, inducing factors and putative genes involved in their biosynthesis and assembly. FEMS Microbiology Reviews, vol. 33, no. 5, pp. 917-941

[19 Pollard, A. J., Reeves, R. D., \& Baker, A. J. M. (2014). Facultative hyperaccumulation of heavy metals and metalloids. Plant Science, pp. 217-218, pp. 8-17

[20] Prasanna, R., Bidyarani, N., Babu, S., Hossain, F., Shivay, Y. S., \& Nain, L. (2015). Cyanobacterial inoculation elicits plant defense response and enhanced Zn mobilization in maize hybrids. Cogent Food \& Agriculture, 1(1), 998507.

[21] Rossi, F., Li, H., Liu, Y., \& De Philippis, R. (2017). Cyanobacterial inoculation (cyanobacterisation): Perspectives for the development of a standardized multifunctional technology for soil fertilization and desertification reversal. EarthScience Reviews, vol. 171, pp. 28-43

[22] Sheoran, V., Sheoran, A., Poonia, P. (2010). Phytoremediation of metal contaminated mining sites. Int J Earth Sci Eng. vol. 5, no.3: pp. 428-436. ISSN 0974-5904

[23] Singh, S. (2014). A review on possible elicitor molecules of cyanobacteria: Their role in improving plant growth and providing tolerance against biotic or abiotic stress. Journal of Applied Microbiology, 117(5), 1221-1244

[24] Smith, G. D., \& Doan, N. T. (1999). Cyanobacterial metabolites with bioactivity against photosynthesis in cyanobacteria, algae and higher plants. Journal of Applied Phycology, 11(4), 337-344.

[25] Walkey, A., \& Black, J. (1947). A critical examination of a rapid method for determining organic carbon in soil. Soil Sci, 63(25): 263.

[26] Wang, L., Ji, B., Hu, Y., Liu, R., \& Sun, W. (2017). A review on in situ phytoremediation of mine tailings. Chemosphere, vol. 184,pp. 594-600

[27] Zhang X., Yang H., Cui Z. (2017). Assessment on Cadmiun and Lead in soil based on rhizosphere microbial community. Toxicol Res. 6:671 